\title{
SPARC overexpression combined with radiation retards angiogenesis by suppressing VEGF-A via miR-410 in human neuroblastoma cells
}

\author{
JERUSHA BOYINENI $^{1 *}$, SMITA TANPURE ${ }^{1 *}$, MANU GNANAMONY ${ }^{1}$, REUBEN ANTONY $^{2}$, \\ KAREN S. FERNÁNDEZ ${ }^{2}$, JULIAN LIN ${ }^{3}$, DAVID PINSON ${ }^{4}$ and CHRISTOPHER S. GONDI ${ }^{1,4,5}$ \\ Departments of ${ }^{1}$ Internal Medicine, ${ }^{2}$ Pediatrics, ${ }^{3}$ Neurosurgery, ${ }^{4}$ Pathology and ${ }^{5}$ Surgery, \\ University of Illinois College of Medicine, Peoria, IL 61605, USA
}

Received April 28, 2016; Accepted July 6, 2016

DOI: 10.3892/ijo.2016.3646

\begin{abstract}
Neuroblastoma (NB) is the most common extracranial solid tumor in children and despite aggressive therapy survival rates remain low. One of the contributing factors for low survival rates is aggressive tumor angiogenesis, which is known to increase due to radiation, one of the standard therapies for neuroblastoma. Therefore, targeting tumor angiogenesis can be a viable add-on therapy for the treatment of neuroblastomas. In the present study, we demonstrate that overexpression of secreted protein acidic and rich in cysteine (SPARC) suppresses radiation induced angiogenesis in SK-N-BE(2) and NB1691 neuroblastoma cells. We observed that overexpression of SPARC in SK-N-BE(2) and NB1691 cells reduced radiation induced angiogenesis in an in vivo mouse dorsal skin model and an ex vivo chicken CAM (chorioallantoic-membrane) model and also reduced tumor size in subcutaneous mouse tumor models of NB. We also observed that SPARC overexpression reduces VEGF-A expression, in SK-N-BE(2) and NB1691 NB cells via miR-410, a VEGF-A targeting microRNA. SPARC overexpression alone or in combination with miR-410 and radiation was shown to be effective at reducing angiogenesis. Moreover, addition of miR-410 inhibitors reversed SPARC mediated inhibition of VEGF-A in NB1691 cells but not in SK-N-BE(2) NB cells.
\end{abstract}

Correspondence to: Dr Christopher S. Gondi, Department of Internal Medicine, University of Illinois College of Medicine at Peoria, 1 Illini Drive, Peoria, IL 61605, USA

E-mail: gondi@uic.edu

*Contributed equally

Abbreviations: SPARC, secreted protein acidic and rich in cysteine; VEGF, vascular endothelial growth factor; CAM chorioallantoicmembrane

Key words: SPARC, neuroblastoma, radiation miR-410, angiogenesis, vascular endothelial growth factor; CAM chorioallantoic-membrane
In conclusion, the present study demonstrates that the overexpression of SPARC in combination with radiation reduced tumor angiogenesis by downregulating VEGF-A via miR-410.

\section{Introduction}

Neuroblastoma is the most common extracranial solid tumor in children and accounts for $15 \%$ of all childhood related cancer deaths (1). Neuroblastoma is clinically heterogeneous, with a subset of patients showing spontaneous tumor regression and another subset of patients showing aggressive progression. Despite intensive multimodal therapy which also includes radiation, the survival rates of patients with high-risk neuroblastoma remain poor (2). Resistance to these therapies and the subsequent aggressive behavior of tumors can be attributed to several factors which include increased migration, invasion and angiogenesis (3). The role of vascular endothelial growth factors (VEGFs) in angiogenesis has been well characterized. Of the several members of the VEGF family, VEGF-A is the best characterized and is considered to be the fundamental mediator of pathologic angiogenesis (4). VEGF-A, aka VEGF is secreted by tumor cells, binds with high affinity to vascular endothelial growth factor receptor 2 (VEGFR2) on endothelial cells, initiates receptor dimerization mediating its phosphorylation, which leads to activation of downstream signaling cascades. This cascade includes key players such as extracellular signal-regulated kinase 1 and 2 (ERK1/2), p38 kinase, and c-Jun N-terminal kinase/stress-activated protein kinase (JNK/SAPK). These players belong to the family of mitogen-activated protein kinases (MAPKs) that promote cell growth and proliferation (5).

Therapeutic strategies for treatment of neuroblastoma have evolved over the years and are generally based on risk grade. The current treatment strategy for high-risk neuroblastoma is multi-modal and is divided into three phases: Induction phase, consolidation phase and the maintenance phase (6). i) Induction phase includes high dose chemotherapy using cisplatin and etoposide alternating with vincristine, cyclophosphamide and doxorubicin (7). ii) Consolidation phase includes surgical resection, myeloablative chemotherapy followed by hematopoietic stem cell rescue/transplantation (HSCT), and 
further followed by radiation. Radiation therapy is given to control local metastatic sites when appropriate (8). iii) The maintenance phase is aimed at targeting residual tumor cells with isotretinoin in combination with immunotherapy such as anti-GD2 antibodies combined with interleukin-2 and GM-CSF. This multimodality approach has been shown to improve event-free survival (EFS) (9) in most cases, however, refractory cases still remain.

Secreted protein acidic and rich in cysteine (SPARC, also known as osteonectin; or basement-membrane-40, BM-40) belongs to a group of non-structural components of the extracellular matrix (ECM) that modulate interactions between cells and their micro-environment. It is highly expressed in a variety of cell types and is associated with tissue remodeling. The role of SPARC in tumorigenesis appears to be dichotomous. In some types of cancer such as breast $(10,11)$, ovarian (12) and gastric cancers (13), high levels of SPARC expression has been shown to correlate with disease progression and poor prognosis. In other types of cancer such as prostate (14), acute myelogenous leukemia (15) and neuroblastoma (16), SPARC functions as a tumor suppressor, making SPARC both a pro- and an anti-oncogenic molecule. In neuroblastomas there is an inverse correlation between SPARC expression and tumor stage (17). Studies have demonstrated that tumorigenic neuroblastoma cell lines showed low or undetectable levels of SPARC, while non-tumorigenic cells expressed high levels of SPARC $(18,19)$, making SPARC overexpression a viable option for neuroblastoma treatment. In addition, SPARC has been shown to have anti-angiogenic properties including the ability to inhibit proliferation and migration of endothelial cells stimulated by bFGF and VEGF (17). This study was aimed at deciphering one of the mechanisms by which SPARC overexpression mediates angiogenic suppression. Here we present our findings that show combination of SPARC overexpression accompanied with radiation reduces VEGF-A induced angiogenesis via the VEGF-A targeting microRNA miR-410 in NB1691 and SK-N-BE(2) neuroblastoma cells.

\section{Materials and methods}

Human neuroblastoma tissue array. Human neuroblastoma tissue arrays were obtained from US Biomax, Inc. (Rockville, MD, USA). The array consisted of 61 cases of neuroblastoma cancer and normal tissues with stage and grade information. Tissue arrays were processed for immunohistochemistry as per previously described standard protocol (20). Briefly, slides were deparaffinized and endogenous peroxidases activity was blocked at room temperature by 5-10 min incubation in $0.3 \% \mathrm{H}_{2} \mathrm{O}_{2}$ in PBS ( $\mathrm{pH} 7.7$ ). The slides were then rinsed in PBS for $5 \mathrm{~min}$, followed by antigen retrieval by heating at $95^{\circ} \mathrm{C}$ in citrate buffer $(0.01 \mathrm{~mol} / 1$ sodium citrate buffer, $\mathrm{pH} 6.0)$ for $10 \mathrm{~min}$. The tissues were blocked using normal goat serum for $20 \mathrm{~min}$ at room temperature and incubated in primary antibody (anti-VEGF or SPARC) for $60 \mathrm{~min}$ at room temperature. The slides were then rinsed in PBS followed by the addition of a horseradish peroxidase (HRP)-conjugated secondary antibody for $20 \mathrm{~min}$ at room temperature. HRP substrate DAB (3,3'-diaminobenzidine tetrahydrochloride) at $1 \mathrm{mg} / \mathrm{ml}$ in $50 \mathrm{mmol} / 1$ Tris, $\mathrm{pH} 7.2$, and $0.3 \% \mathrm{H}_{2} \mathrm{O}_{2}$ was then added for the development of DAB substrate followed by haematoxylin staining. Next, the slides were dehydrated and mounted with coverslips.

Cell lines and culture conditions. Neuroblastoma cell line SK-N-BE(2) [obtained from the American Type Culture Collection (ATCC; Manassas, VA, USA)] was obtained, characterized and authenticated by the ATCC, low passage cells were used for experiments in all the cases (less than 6 months of passages) and NB1691 (provided by Peter Houghton, St. Jude Children's Research Hospital, Memphis, TN, USA) were characterized and authenticated by the providers institution (less than 6 months of passages) were cultured in Opti-MEM medium with 5\% fetal bovine serum (FBS) and $1 \%$ penicillin/streptomycin in a humidified $5 \%$ atmospheric $\mathrm{CO}_{2}$ at $37^{\circ} \mathrm{C}$. Endothelial cells were cultured using the endothelial cell growth Medium-200 (Thermo Fisher Scientific, Waltham, MA, USA) with $10 \mathrm{ng} / \mathrm{ml} \mathrm{EGF,} 10 \mathrm{ng} / \mathrm{ml} \mathrm{FGF}$, $10 \mathrm{ng} / \mathrm{ml}$ heparin, and $1 \mu \mathrm{g} / \mathrm{ml}$ of hydrocortisone, $2 \% \mathrm{FBS}$ and $1 \%$ penicillin/streptomycin in a humidified $5 \% \mathrm{CO}_{2}$ atmosphere at $37^{\circ} \mathrm{C}$ with Calcein AM Dye (Thermo Fisher Scientific) as per manufacturer's instructions.

SPARC overexpression. SK-N-BE(2) and NB1691 cells were transfected with SPARC overexpression plasmid RC209964 (Origene Technologies, Inc., Rockville, MD, USA) as per standard protocols using Lipofectamine with $10 \mu \mathrm{g}$ of plasmid on $60 \%$ confluent plates. SPARC overexpression was also validated in vitro using SPARC Adenovirus (Human) from Applied Biological Materials Inc., (Richmond, BC, Canada) on $60 \%$ confluent plates at $50 \mathrm{MOI}$ infection. Empty adenovirus was used as control. SPARC expression was validated by western blot analysis.

Antibodies. Antibodies were obtained from the following sources: SPARC (Aviva Systems Biology Corp., San Diego, CA, USA), VEGF-A and $\beta$-actin (Santa Cruz Biotechnology, Dallas, TX, USA).

Western blotting. SK-N-BE(2) and NB1691 cells were transfected with SPARC overexpression plasmid. After $24 \mathrm{~h}$, cells were treated with or without 5 Gy of ionizing radiation and incubated for another $24 \mathrm{~h}$. Cells were collected and total protein extracted by using M-PER mammalian protein extraction reagent (Thermo Fisher Scientific, Waltham, MA, USA) and protein concentrations measured using Pierce $660 \mathrm{~nm}$ protein assay reagent (Thermo Fisher Scientific). Equal amounts of protein (10 $\mu \mathrm{g} /$ lane) were electrophoresed under reducing conditions on $4-16 \%$ gradient polyacrylamide gels. After SDS-PAGE, the separated proteins were transferred on to a polyvinylidene difluoride membrane (Bio-Rad Laboratories, Hercules, CA, USA). Membranes were blocked with TBS-T containing 5\% non-fat skim milk for $1 \mathrm{~h}$. Subsequently, membranes were immunoprobed with primary antibody and appropriate horseradish peroxidase-labelled secondary antibody. Specific protein bands were visualized using enhanced chemiluminescence detection reagents (Life Technologies, Carlsbad, CA, USA). A similar protocol was used for total protein isolated from subcutaneous tumors of nude mice described in section below (see method for neuroblastoma subcutaneous tumor model). 
In vitro angiogenesis assay. To determine in vitro angiogenic inhibition by SPARC overexpression in neuroblastoma cells, we collected conditioned media from controls or radiated NB1691 and SK-NB-E(2) cells with or without SPARC overexpression as per standard protocols. The collected conditioned media $(100 \mu \mathrm{l})$ was used to culture human endothelial cells over Matrigel. As a positive control for VEGF-A inhibition, we used $50 \mu \mathrm{g} / \mathrm{ml}$ of bevacizumab a recombinant humanized monoclonal antibody that targets VEGF-A in control NB1691 or SK-N-BE(2) conditioned media to compare angiogenic inhibition with SPARC overexpression. The cells were monitored every hour for network formation and after $6 \mathrm{~h}$ endothelial cell network was visualized at $490 \mathrm{~nm}$ excitation and $520 \mathrm{~nm}$ emission using an inverted fluorescent microscope. Angiogenesis was quantified by determining the number of branch points as per standard protocols.

Animals. BALB/c nude female mice aged 6-8 weeks were obtained from Harlen Labs, Inc. (Indianapolis, IN, USA) and housed in micro-isolation cages in groups of five animals in ventilated racks at a constant temperature of $20-26^{\circ} \mathrm{C}$ and humidity of $30-70 \%$. All animal experiments were carried out after obtaining approval from the Institutional Animal Care and Use Committee.

In vivo angiogenesis assay. The in vivo angiogenic assay was done as previously described with minor modifications (20). SK-N-BE(2) or NB1691 cells $\left(1 \times 10^{6}\right)$ treated with SPARC overexpressing plasmid alone or with radiation were loaded into a diffusing chamber. A 2-cm long incision was made horizontally along the edge of the dorsal air sac of the mice and the chambers were placed underneath the skin. The mice were sacrificed 10 days later; and carefully skinned around the implanted chambers. The skin folds covering the chambers were photographed under visible light, and tumor induced vasculature quantified.

Neuroblastoma subcutaneous tumor model. The subcutaneous tumor model was done as previously described by us with minor modifications (21). SK-N-BE(2) and NB1691 cells were implanted subcutaneously into nude mice on day 0 ( $1 \times 10^{5}$ cells). After 25 days, animals developed detectable tumors. Mice were separated into 4 groups of 5 animals per group. The animals that lost $\geq 20 \%$ of body weight or had trouble ambulating, feeding or grooming were sacrificed. On day 28 and day 32, two groups of animals received $150 \mu \mathrm{g} /$ animal per day intratumoral injection of SPARC plasmid DNA given at three different locations on the tumor (plasmid concentration of $1.5 \mu \mathrm{g} / \mu \mathrm{l}$ in PBS, $50 \mu \mathrm{g}$ per site $120^{\circ}$ apart) at a depth of 3-5 mm using a 30-gauge insulin syringe. The overall cumulative dose was $300 \mu \mathrm{g} / \mathrm{animal}$. Two groups were left as controls. On day 30, one group each of SPARC treated and control animals were exposed to $5 \mathrm{~Gy}$ ionizing radiation. Tumor growth was followed, till day 45, after which animals were sacrificed. Tumors were harvested, imaged followed by, protein and total RNA isolation by standard protocols. Tumors were fixed in buffered formaldehyde and paraffin sectioned for immunohistochemical analysis of SPARC and VEGF-A. In vivo tumor size measurement: Subcutaneous tumors volumes were measured using the following formula: $\pi / 6\left(\mathrm{Lx} \mathrm{W}^{2}\right)$ where $\mathrm{L}$ is the length and $\mathrm{W}$ is the width.
Table I. PCR primers.

\begin{tabular}{ll}
\hline Primer name & \multicolumn{1}{c}{ Sequence (5'-3') } \\
\hline VEGF-A-F & AGGAGGAGGGCAGAATCATCA \\
VEGF-A-R & CTCGATTGGATGGCAGTAGCT \\
VEGFB-F & GAGATGTCCCTGGAAGAACACA \\
VEGFB-R & GAGTGGGATGGGTGATGTCAG \\
VEGFC-F & GGCTGGCAACATAACAGAGAA \\
VEGFC-R & CCCCACATCTATACACACCTCC \\
FGF2-F & AGAAGAGCGACCCTCACATCA \\
FGF2-R & CGGTTAGCACACACTCCTTTG \\
ANGPT1-F & AGAACCTTCAAGGCTTGGTTAC \\
ANGPT1-R & GGTGGTAGCTCTGTTTAATTGCT \\
ANGPT2-F & CTCGAATACGATGACTCGGTG \\
ANGPT2-R & TCATTAGCCACTGAGTGTTGTTT \\
PDGF-F & GCAAGACCAGGACGGTCATTT \\
PDGF-R & GGCACTTGACACTGCTCGT \\
HPRT1-F & TGACACTGGCAAAACAATGCA \\
HPRT1-R & GGTCCTTTTCACCAGCAAGCT \\
\hline
\end{tabular}

Immunohistochemistry. Excised tumors were fixed in $10 \%$ buffered formalin and embedded in paraffin. Tissue sections (5 $\mu \mathrm{m}$ thick) collected on slides were deparaffinized and endogenous peroxidases activity was blocked at room temperature by $5-10 \mathrm{~min}$ of incubation in $0.3 \% \mathrm{H}_{2} \mathrm{O}_{2}$ in $\mathrm{PBS}(\mathrm{pH}$ 7.7). The slides were then rinsed in PBS for $5 \mathrm{~min}$, followed by antigen retrieval by heating to $95^{\circ} \mathrm{C}$ in citrate buffer $(0.0 \mathrm{~mol} / 1$ sodium citrate buffer, $\mathrm{pH}$ 6.0) for $10 \mathrm{~min}$. The tissues were blocked using normal goat serum for $20 \mathrm{~min}$ at room temperature and incubated in primary antibody (anti-VEGF or SPARC) for $60 \mathrm{~min}$ at room temperature. The slides were then rinsed in PBS followed by the addition of a horseradish peroxidase (HRP)-conjugated secondary antibody for $20 \mathrm{~min}$ at room temperature. HRP substrate DAB (3,3'-diaminobenzidine tetrahydrochloride) at $1 \mathrm{mg} / \mathrm{ml}$ in $50 \mathrm{mmol} / 1$ Tris, $\mathrm{pH} \mathrm{7.2,}$ and $0.3 \% \mathrm{H}_{2} \mathrm{O}_{2}$ was then added for the development of DAB substrate followed by haematoxylin staining. Next, the slides were dehydrated and mounted with coverslips. Negative control slides were obtained by treating with non-specific IgG. Sections were mounted and analyzed using an inverted microscope. The intensity of VEGF-A or SPARC expression per unit area was measured in arbitrary pixel units using ImageJ software.

Real-time PCR. Total RNA was extracted from the tissue samples using mirVana ${ }^{\mathrm{TM}}$ miRNA isolation kit (Ambion-Life Technologies, Carlsbad, CA, USA). cDNA was synthesized from RNA using miScript II RT kit (Qiagen, Valencia, CA, USA) according to the manufacturer's instructions. Realtime PCR was performed using miScript SYBR-Green PCR kit in an automated thermal cycler (Bio-Rad Laboratories). miR-410 and SNORD68 primers were obtained from Qiagen. SNORD68 was used as an internal control for normalization. The expression levels of pro-angiogenic factors VEGF-A, -B, -C, FGF2, PDGF, ANGPT1 and ANGPT2 (Table I) were measured as per standard protocol and normalized to HPRT. Relative gene expression was calculated by the $2^{-\Delta \mathrm{Ct}}$ method. 
Inhibition of miR-410 expression. MicroRNA transfection reagent, $\mathrm{miR}$-410 mimic (AAUAUAACACAGAUGGCCUGU) and miR-410 inhibitors (UUAUAUUGUGUCUACCGGACA) were obtained from Sigma-Aldrich (St. Louis, MO, USA). SK-N-BE(2) and NB1691 were transfected as per the manufacturer's instructions and conditioned media from these cells were used in CAM assay or for ELISA determination of VEGF-A protein levels. To determine the effectiveness of miR-410 inhibition, miR-410 inhibitor treated cells were assayed for the expression levels of miR-410 using RT-PCR as per standard protocols and normalized to SNORD68 expression.

Chicken chorioallantoic membrane (CAM) assay. Fertilized white leghorn chicken eggs were obtained from Charles River Laboratories (Wilmington, MA, USA) and incubated at $37^{\circ} \mathrm{C}$ with $60 \%$ humidity. On day 7 , a small window was made on the egg shell under aseptic conditions. Sterile filter paper disks (Whatman, 1-2 mm size) were placed on top of the CAM. Conditioned medium collected from SK-N-BE(2) and NB1691 cells were added on top of the filter disks, gap sealed with porous adhesive tape and the eggs were returned to the incubator. On day 12, CAM surrounding the filter disk was carefully removed, placed on glass slides and visualized for angiogenesis using a stereomicroscope. Angiogenesis was quantified by measuring the length of newly formed capillaries by using imageJ software.

$V E G F-A$ ELISA. Protein levels of VEGF-A were determined from the conditioned media of SK-N-BE(2) and NB1691 cells overexpressed for SPARC with or without miR-410 inhibitor using the VEGF-A ELISA kit from Thermo Fisher Scientific as per manufacturer's protocols.

Statistical analysis. All data are expressed as mean \pm SD. Statistical analysis was performed using Student's t-test. A P-value of $\leq 0.05$ was considered statistically significant. All experiments were performed in triplicate, or as indicated.

\section{Results}

Expression of VEGF-A in human neuroblastoma tissues is inversely proportional to the expression of SPARC. Human neuroblastoma tissue array from US Biomax, Inc., consisting of 61 neuroblastoma cases, was processed for immunohistochemistry for the expression of VEGF-A and SPARC as previously described (20). From the tissue array, we observed that the expression of SPARC was always inversely correlated with the expression of VEGF-A (Fig. 1A). Further semiquantification of expression of SPARC and VEGF-A in the human tissue array reveled that higher expression of SPARC correlated with retroperitoneal tumors rather than with tumors in the abdominal cavity, mediastinum, or adrenal gland (data not shown).

Overexpression of SPARC combined with radiation suppresses angiogenesis. The role of SPARC in angiogenesis has been demonstrated by us and other researchers $(22,23)$. The addition of radiation treatment was included because radiation induced vascular injury can promote the development of leaky vasculature that can contribute to local hypoxic regions promoting an angiogenic response (24-26). Therefore, targeting angiogenesis accompanied with radiation would greatly impact the success of the consolidation therapy phase (6). As we have observed that VEGF-A is a significant player in angiogenesis in neuroblastomas and that expression of SPARC is always inversely correlated with the expression of VEGF-A (Fig. 1A), overexpression of SPARC could be a strategy for controlling radiation induced angiogenesis that is mediated by VEGF-A. To determine whether overexpression of SPARC suppressed angiogenesis, we performed the dorsal skin fold angiogenesis assay using nude mice as previously described (20). We observed that control mice showed increased tumor induced vasculature (TV) which was clearly differentiated from pre-existing vasculature (PV). Neuroblastoma tumor that overexpressed SPARC showed a significantly reduced amount of tumor induced vasculature $(20 \%)$ in both NB1691 cells $(\mathrm{P}<0.001)$ and in SK-N-BE(2) $(50 \%)$ cells $(\mathrm{P}<0.05)$. Addition of radiation treatment along with SPARC further suppressed tumor cell induced vasculature by $94 \%$ in NB1691 cells $(\mathrm{P}<0.001)$ and by $85 \%$ in SK-N-BE $(2)$ cells $(\mathrm{P}<0.001)$ (Fig. $1 \mathrm{~B}$ and $\mathrm{C})$. Notably, addition of radiation alone, did increase tumor cell induced vasculature to $110 \%(\mathrm{P}=0.07)$ in $\mathrm{NB} 1691$ and to $128 \%(\mathrm{P}=0.01)$ in $\mathrm{SK}-\mathrm{N}-\mathrm{BE}(2)$ of controls in the dorsal sac chamber nude mouse models.

Both SK-N-BE(2) and NB1691 neuroblastoma cells overexpress $V E G F-A$. Based on the results from the in vivo angiogenic assay, we attempted to validate the involvement of VEGF-A as a significant angiogenic contributor in SK-N-BE(2) and NB1691 neuroblastoma cell lines. We performed RT-PCR to determine the expression levels of known pro-angiogenic molecules VEGF-A, -B, -C, FGF2, PDGF, ANGPT1 and ANGPT2 (Table I) (27) and observed that expression of VEGF-A was significantly higher than the expression levels of VEGF-B, -C, FGF2, PDGF, ANGPT1 or ANGPT2 in both SK-N-BE(2) and NB1691 cells (Fig. 1D). Since the expression of VEGF-A is the prominent contributor of angiogenesis; we further investigated whether the suppression of angiogenesis by SPARC is mediated by modulation of VEGF-A expression.

SPARC overexpression suppresses tumor growth and VEGF-A expression. As we determined that VEGF-A is a major contributor to angiogenesis in both SK-N-BE(2) and NB1691 cells (Fig. 1D), and in continuation with this finding and our previous findings (22), we attempted to determine whether SPARC expression can suppress tumor growth and angiogenesis by modulating the expression of VEGF-A. We performed immunohistochemical analysis for VEGF-A and SPARC on neuroblastoma subcutaneous tumors developed in mice from SK-N-BE(2) or NB1691 neuroblastoma cells (Fig. 2A and B). As described, SK-N-BE(2) and NB1691 cells were implanted subcutaneously into nude mice followed by intratumoral injection of SPARC plasmid DNA (150 $\mu \mathrm{g} /$ animal) and/or 5 Gy ionizing radiation. Tumors were harvested after 45 days, and we observed that mice radiated with 5 Gy showed slightly larger tumors when compared to non-radiated controls. SPARC overexpression plasmid treated mice showed decreased tumor size in NB1691 tumors but not so much in SK-N-BE(2) tumors. Furthermore, mice treated with both radiation and SPARC overexpression showed the greatest decrease in tumor growth 
A

$\begin{array}{lllllllllll}1 & 2 & 3 & 4 & 5 & 6 & 7 & 8 & 9 & 10\end{array}$

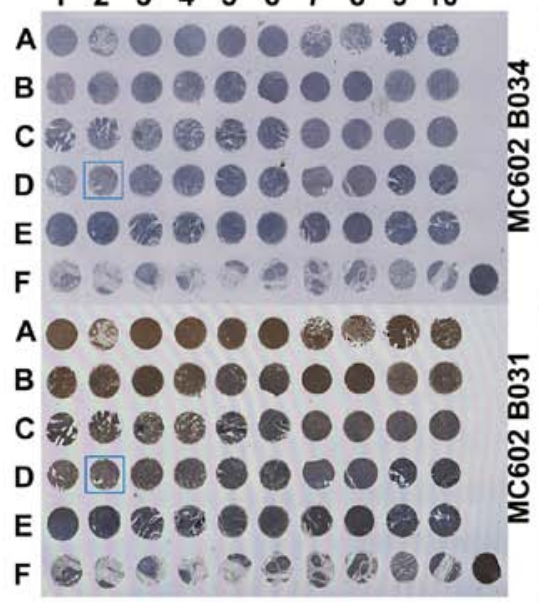

B
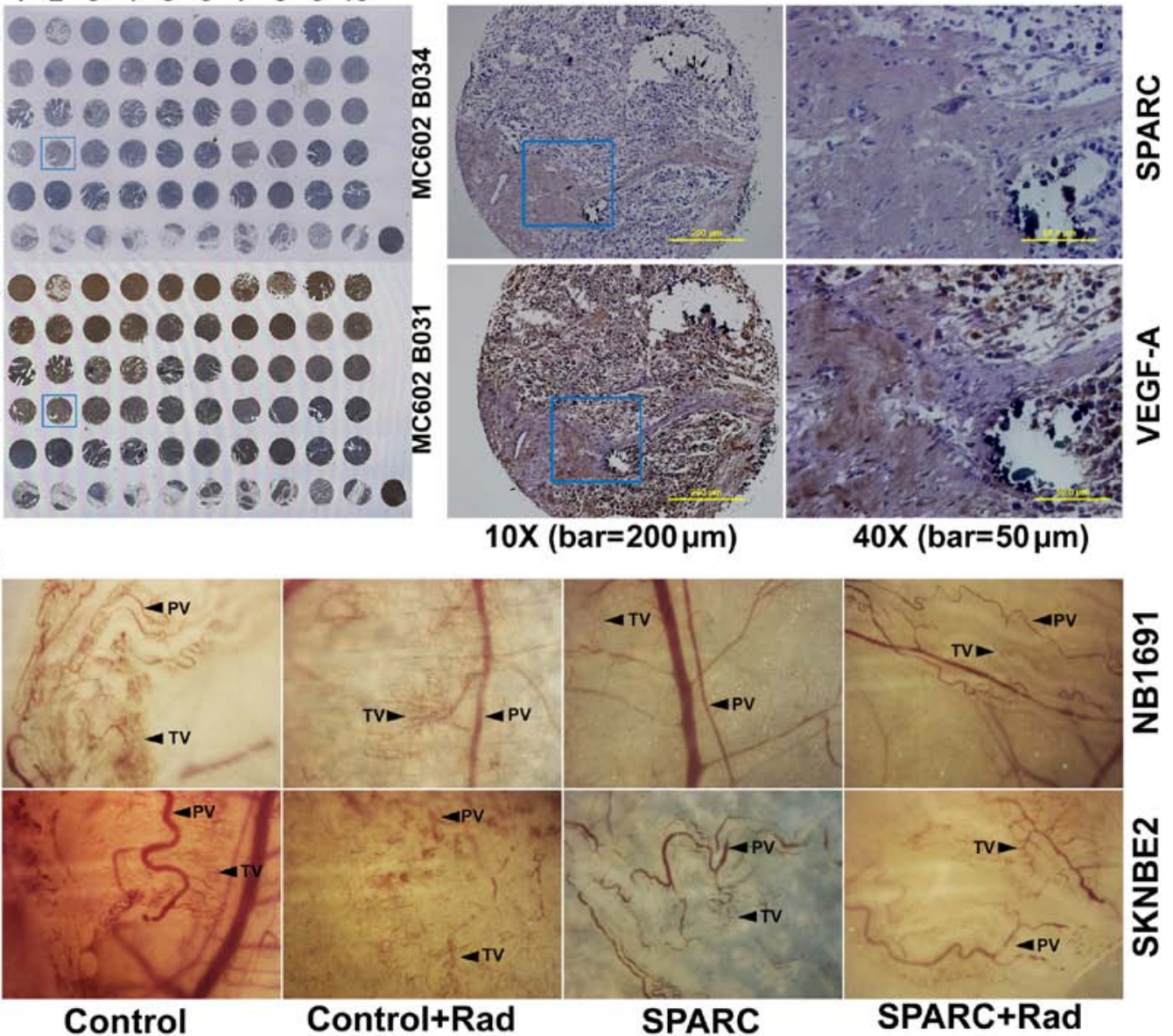

C
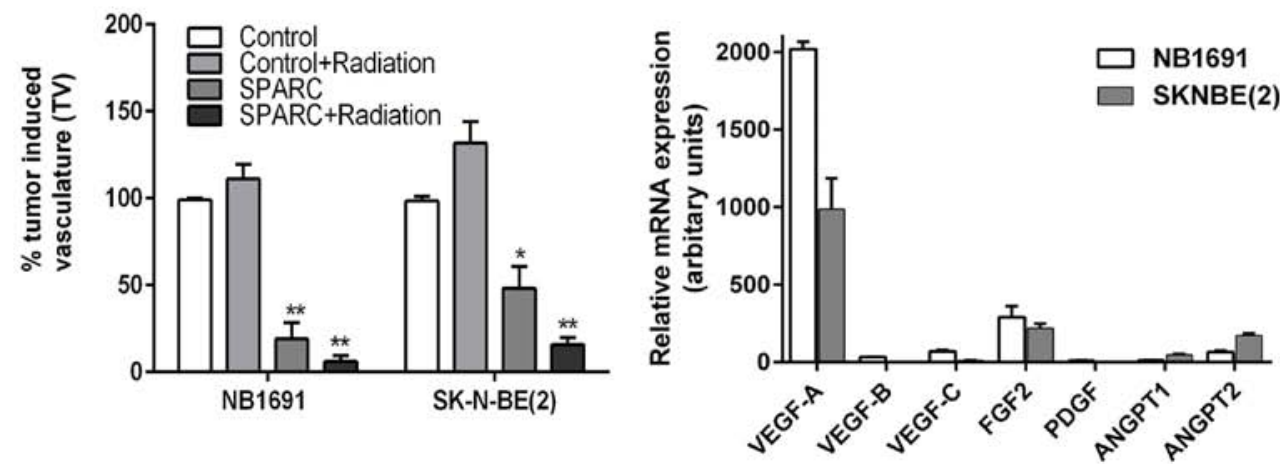

Figure 1. SPARC upregulation combined with radiation reduces VEGF-mediated angiogenesis in vivo. Expression of VEGF-A and SPARC was determined on human tissue array using the HRP substrate DAB. (A) Tissue arrays were processed for immunohistochemistry and expression of VEGF-A and SPARC are shown. Angiogenic potential of SK-N-BE(2) and NB1691 cell lines was determined using the dorsal skin fold assay. (B) Pre-existing vasculature (PV) and tumor-induced vasculature (TV) are indicated. (C) TV was quantified as density of newly formed vessels and represented as arbitrary pixel units (control vs. SPARC and control vs. SPARC + radiation, $\left.{ }^{*} \mathrm{P}<0.05,{ }^{* *} \mathrm{P}<0.001\right)$. To determine the most prominent pro-angiogenic molecule expressed in $\mathrm{SK}-\mathrm{N}-\mathrm{BE}(2)$ and NB1691 cell lines, RT-PCR analysis of known pro-angiogenic molecule was done. Expression levels of pro-angiogenic mRNA levels were quantified and graphically represented (D).

with two of the five mice showing undetectable tumors in both NB1691 and SK-N-BE(2) implanted mice (Fig. 2B and C). Furthermore, we observed that the expression of SPARC and VEGF-A were inversely correlated (Fig. 2D) and was similar to the human tissue array expression of SPARC and VEGF-A (Fig. 1A), where we observed that the expression of SPARC and VEGF-A was inversely correlated. Graphical representation of VEGF-A expression obtained by determining the pixel intensity of HRP-DAB reaction showed that SPARC overexpression strongly inhibited VEGF-A expression in both SK-N-BE $(2)(\mathrm{P}<0.05)$ and NB1691 $(\mathrm{P}<0.05)$ neuroblastoma subcutaneous tumors (Fig. 3A). Addition of radiation further reduced VEGF-A levels in SK-N-BE $(2)(\mathrm{P}<0.001)$ and NB1691 $(\mathrm{P}<0.001)$ derived tumors (Fig. 3A). Furthermore, mice injected with SPARC overexpressing plasmids did show increased expression of SPARC $(\mathrm{P}<0.001)$ (Fig. 3B). To vali- 


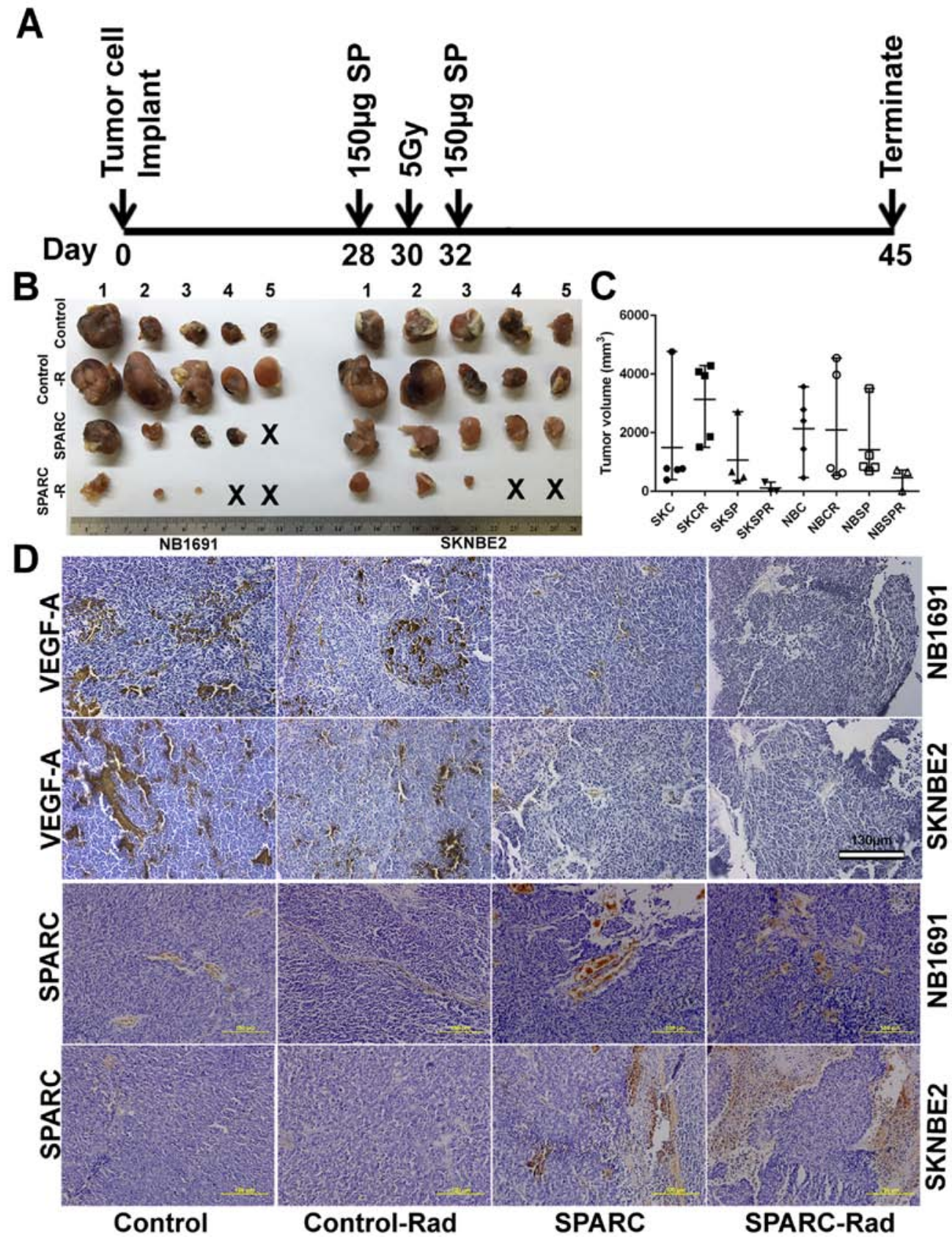

Figure 2. Overexpression of SPARC and low-dose radiation in NB1691 and SK-N-BE(2) subcutaneous tumors suppresses tumor growth. Time line showing neuroblastoma tumor implantation and SPARC treatment with or without radiation in nude mice (A), 45 days after tumor development, tumors were harvested and volumes were measured (B). (C) (SKC, SK-N-BE(2) control; SKCR, SK-N-BE(2) + 5 Gy radiation; SKSP, SK-N-BE(2) + SPARC overexpression; SKSPR, SK-N-BE(2) + SPARC overexpression + 5 Gy radiation; NBC, NB1691 control; NBCR, NB1691 + 5 Gy radiation; NBSP, NB1691 + SPARC overexpression; NBSPR, NB1691 + SPARC overexpression + 5 Gy radiation). (D) After formalin fixation the tumors were processed for paraffin sectioning and VEGF-A and SPARC expression levels were visualized by immunohistochemistry.

date the immunohistochemistry data, proteins were extracted from these tumors and expression levels of SPARC and VEGF-A determined by western blot analysis (Fig. 3C). This also correlated well with the human tissue array data (Fig. 1A) and the immunohistochemistry data (Fig. 2D). To further validate these findings, we performed western blots for VEGF-A and SPARC on NB1691 and SK-N-BE(2) cells infected with adenovirus expressing SPARC at $50 \mathrm{MOI}$ with and without radiation. We observed that upregulation of SPARC resulted in significant reduction of VEGF-A expression in both NB1691 and SK-N-BE(2) cells (Fig. 3D). To determine whether the suppression of angiogenesis was similar to bevacizumab, we treated human endothelial cells with conditioned media from NB1691 or SK-N-BE(2) cells with or without SPARC overexpression and with or without radiation. We used bevacizumab, a known VEGF-A inhibitor as a positive control. We observed that angiogenic inhibition by overexpression of SPARC was comparable to cells treated with bevacizumab both with and without radiation (Fig. 3E and F).

$S P A R C$ regulates $V E G F-A$ mediated angiogenesis through $m i R-410$. VEGF-A is a major contributor of angiogenesis and is a recognized therapeutic target (28-30). Our data from miRanda analysis presented shows that miR-410 is a signifi- 
A

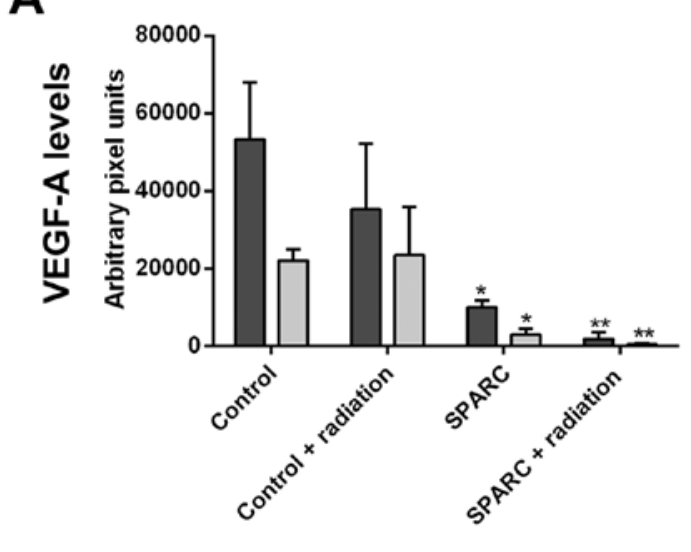

B

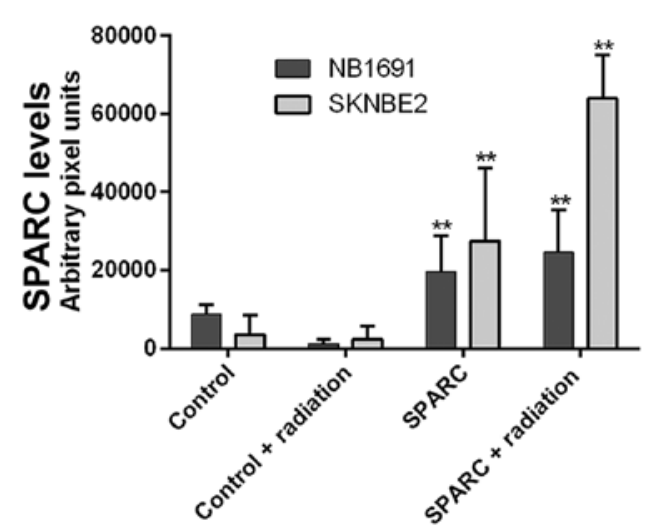

E

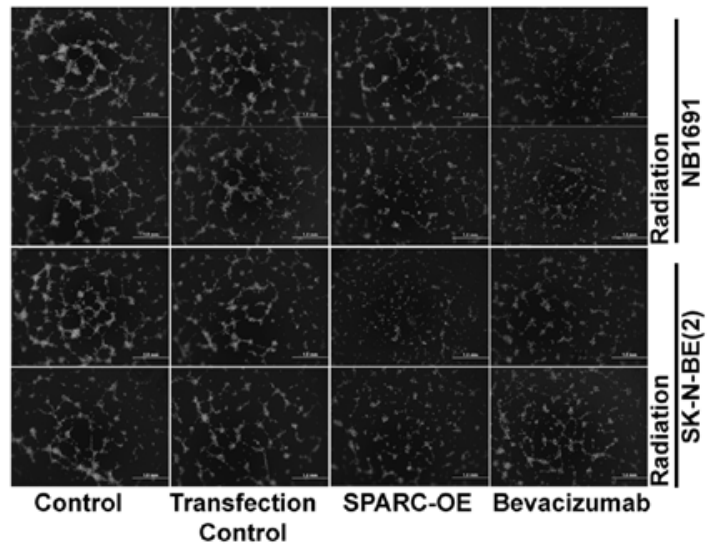

C

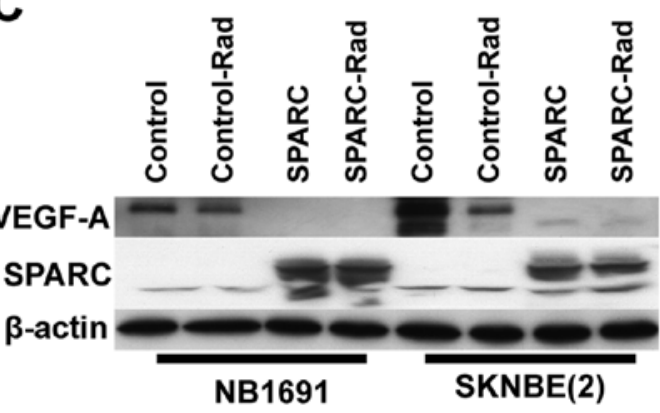

D

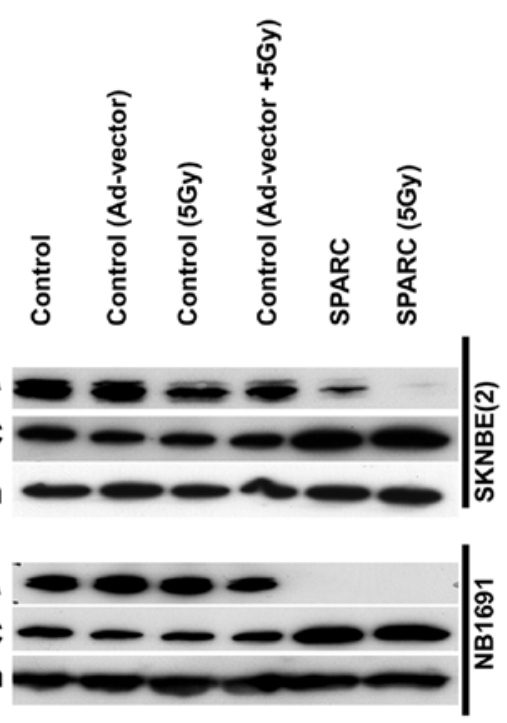

$\mathbf{F}$

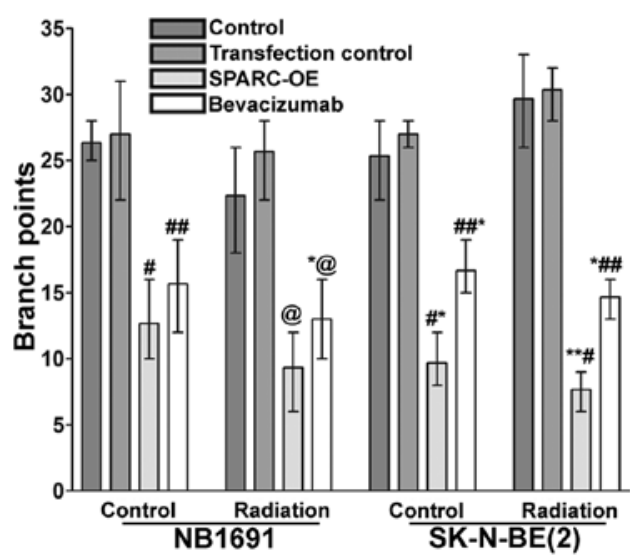

Figure 3. Overexpression of SPARC and low-dose radiation suppresses NB1691 and SK-N-BE(2) VEGF-A expression. SPARC and VEGF-A expression from paraffin sections of NB1691 and SK-N-BE(2) tumors were quantified by ImageJ and represented as arbitrary pixel units. SPARC overexpression resulted in significant reduction of VEGF-A expression, radiation further decreased SPARC induced reduction of VEGF-A (control vs. SPARC and control vs. SPARC + radiation, $\left.{ }^{*} \mathrm{P}<0.05,{ }^{* *} \mathrm{P}<0.001\right)(\mathrm{A})$. Semi-quantitative analysis showing increase of SPARC expression when treated with SPARC overexpressing plasmid (control vs. SPARC and control vs. SPARC + radiation $\left.{ }^{* *} \mathrm{P}<0.001\right)(\mathrm{B})$. Western blotting for VEGF-A and SPARC in NB1691 and SK-N-BE(2): subcutaneous tumors treated with SPARC overexpression plasmid with or without radiation showed decrease in levels of VEGF-A (C). Similarly, increased SPARC expression along with radiation greatly reduced the expression of VEGF-A in both SK-N-BE(2) and NB1691 cell lines (D). In vitro angiogenic inhibition by SPARC overexpression was compared to bevacizumab using endothelial cells cultured over Matrigel in NB1691 and SK-N-BE(2) conditioned media as indicated (E). Quantative analysis for angiogenic inhibition revealed that SPARC overexpression (OE) was comparable to bevacizumab treatments in both NB1691 (control vs. SPARC-OE ${ }^{\#} \mathrm{P}=0.05$, control vs. bevacizumab ${ }^{\# \#} \mathrm{P}=0.06$, control vs. SPARC-OE radiated ${ }^{\circledR} \mathrm{P}=0.02$ and control vs. bevacizumab radiated $\left.{ }^{*,} \mathrm{P}=0.03\right)$ and SK-N-BE(2) (control vs. SPARC-OE ${ }^{*} \mathrm{P}=0.005$, control vs. bevacizumab ${ }^{\# \#, *} \mathrm{P}=0.004$, control vs. SPARC-OE radiated ${ }^{* * * * *} \mathrm{P}=0.004$ and control vs. bevacizumab radiated $\left.{ }^{* \# \# ~} \mathrm{P}=0.0002\right)$ cells $(\mathrm{F})$.

cant modulator of VEGF-A expression (Table II). To validate this in a biological setting, we investigated the relevance of miR-410 as an angiogenic regulator using a chicken chorioal- lantoic membrane (CAM) assay (Fig. 4A), which is an accepted model for in vivo angiogenesis (31). We observed that NB1691 and SK-N-BE(2) cells treated with SPARC reduced angiogen- 
Table II. The miRNAs targeting VEGF-A.

\begin{tabular}{|c|c|c|}
\hline MicroRNA & Position & No. of sites \\
\hline hsa-miR-410 & $344,359,390,1632$ & 4 \\
\hline hsa-miR-590-3p & 1375 & 1 \\
\hline hsa-miR-374a & 355 & 1 \\
\hline hsa-miR-429 & 1286 & 1 \\
\hline hsa-miR-185 & 1396,1686 & 2 \\
\hline hsa-miR-383 & 1900 & 1 \\
\hline hsa-miR-361-5p & 1604 & 1 \\
\hline hsa-miR-186 & 410 & 1 \\
\hline hsa-miR-300 & $1366,1553,1879$ & 3 \\
\hline hsa-miR-381 & $1366,1553,1883$ & 3 \\
\hline hsa-miR-424 & 262 & 1 \\
\hline hsa-miR-29a & 1730 & 1 \\
\hline hsa-miR-29b & 1729 & 1 \\
\hline hsa-miR-29c & 1730 & 1 \\
\hline hsa-miR-497 & 263 & 1 \\
\hline hsa-miR-15b & 262 & 1 \\
\hline hsa-miR-374b & 357 & 1 \\
\hline hsa-miR-15a & 260 & 1 \\
\hline hsa-miR-200b & 1284 & 1 \\
\hline hsa-miR-200c & 1283 & 1 \\
\hline hsa-miR-16 & 261 & 1 \\
\hline hsa-miR-195 & 264 & 1 \\
\hline hsa-miR-299-3p & 329 & 1 \\
\hline hsa-miR-494 & 1382 & 1 \\
\hline hsa-miR-140-5p & 1053 & 1 \\
\hline hsa-miR-205 & 138 & 1 \\
\hline hsa-miR-134 & 1412 & 1 \\
\hline hsa-miR-340 & $342,388,1635$ & 3 \\
\hline hsa-miR-495 & 1708 & 1 \\
\hline hsa-miR-1 & 1496 & 1 \\
\hline hsa-miR-206 & 1496 & 1 \\
\hline hsa-miR-613 & 1497 & 1 \\
\hline hsa-miR-339-5p & 518,1150 & 2 \\
\hline hsa-miR-329 & 1562 & 1 \\
\hline hsa-miR-362-3p & 1562 & 1 \\
\hline hsa-miR-141 & 1197 & 1 \\
\hline hsa-miR-203 & 1305 & 1 \\
\hline hsa-miR-382 & 1550 & 1 \\
\hline hsa-miR-20a & 164 & 1 \\
\hline hsa-miR-20b & 164 & 1 \\
\hline hsa-miR-93 & 162 & 1 \\
\hline hsa-miR-106a & 164 & 1 \\
\hline hsa-miR-106b & 166 & 1 \\
\hline hsa-miR-17 & 164 & 1 \\
\hline hsa-miR-519d & 164 & 1 \\
\hline hsa-miR-144 & 1735 & 1 \\
\hline hsa-miR-505 & 1096 & 1 \\
\hline hsa-miR-503 & 261 & 1 \\
\hline hsa-miR-543 & 435 & 1 \\
\hline hsa-miR-103 & 260,800 & 2 \\
\hline hsa-miR-107 & 260,800 & 2 \\
\hline hsa-miR-23a & 1597 & 1 \\
\hline
\end{tabular}

Table II. Continued.

\begin{tabular}{lcc}
\hline MicroRNA & Position & No. of sites \\
\hline hsa-miR-23b & 1597 & 1 \\
hsa-miR-486-5p & 717 & 1 \\
hsa-miR-342-3p & 1088 & 1 \\
hsa-miR-125a-5p & 4 & 1 \\
hsa-miR-125b & 11 & 1 \\
hsa-miR-150 & 484 & 1 \\
hsa-miR-199b-5p & 451 & 1 \\
hsa-miR-200a & 1197 & 1 \\
hsa-miR-199a-5p & 454 & 1 \\
hsa-miR-101 & 1733 & 1 \\
hsa-miR-373 & 163 & 1 \\
hsa-miR-520e & 163 & 1 \\
hsa-miR-125a-3p & 873 & 1 \\
hsa-miR-302a & 161 & 1 \\
hsa-miR-302b & 161 & 1 \\
hsa-miR-302c & 157 & 1 \\
hsa-miR-372 & 158 & 1 \\
hsa-miR-520a-3p & 161 & 1 \\
hsa-miR-302e & 167 & 1 \\
\hline
\end{tabular}

esis when compared to controls in both NB1691 $(\mathrm{P}<0.001)$ and SK-N-BE(2) cells $(\mathrm{P}<0.001)$ (Fig. 4B and $C)$. Interestingly, we also found that miR-410 mimic (AAUAUAACACAGAU GGCCUGU) alone showed the same angiogenic inhibitory effect in both NB1691 $(\mathrm{P}<0.001)$ and SK-N-BE(2) cells $(\mathrm{P}<0.001)$ (Fig. 4B and $\mathrm{C})$. To study if this inhibition of angiogenesis is specifically controlled by miR-410, we inhibited miR-410 using a specific inhibitor (UUAUAUUGUGUCU ACCGGACA) in SPARC overexpressing cells. Inhibition of miR-410 reversed SPARC induced reduction of angiogenesis in both NB1691 $(\mathrm{P}<0.001)$ and SK-N-BE $(2)$ cells $(\mathrm{P}<0.001)$ (Fig. 4B and C). This reversal of angiogenic vessel formation was also consistent in the presence of radiation. These findings clearly show that SPARC downregulates VEGF-A mediated angiogenesis specifically by upregulating the expression of miR-410. The P-values represent change in vessel length in 5 replicates. Similar to the in vivo dorsal skin assay where we observed that radiation increased tumor cell induced vasculature, in the CAM assay also we observed that radiation treated cells induced an angiogenic response greater than non-radiated cells. This radiation induced angiogenesis in the CAM ex vivo model was, however, not as pronounced as seen in the in vivo model.

SPARC overexpression upregulates miR-410 (a microRNA that targets $V E G F-A)$. To test whether SPARC regulates VEGF-A expression via microRNAs, we first performed a target prediction analysis using the miRanda algorithm (32) and determined that miR-410 can be a potential mediator for VEGF-A suppression. Of several miRNAs that had potential target regions in the VEGF-A mRNA, miR-410 targeted 4 specific regions of VEGF-A mRNA (Fig. 4D). To study if SPARC was associated with miR-410 expression, we measured 


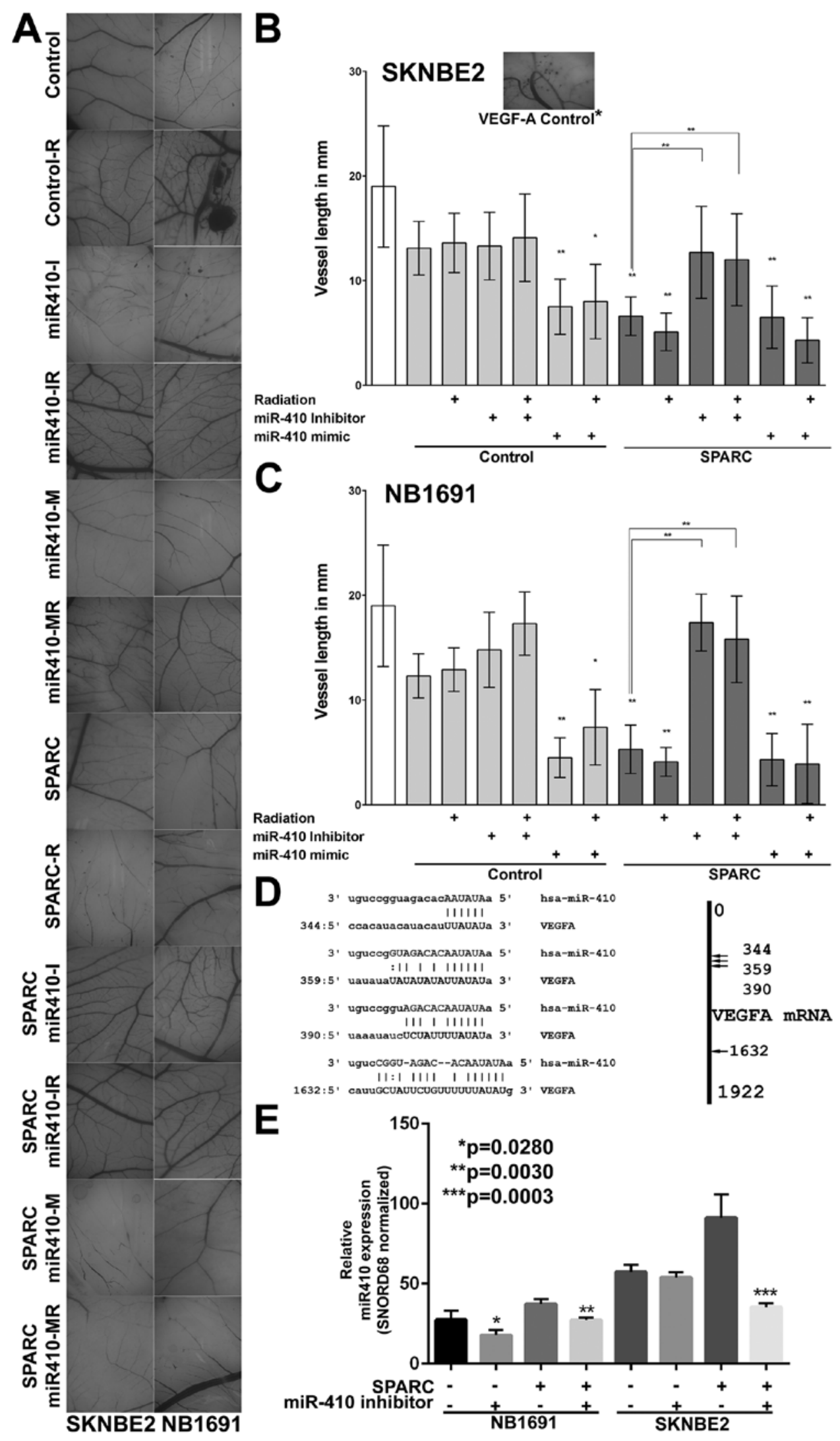

Figure 4. VEGF-A is the target of miR-410. Chicken chorioallantoic membrane (CAM) assay was used to determine the angiogenic potential of conditioned medium from SK-N-BE(2) and NB1691 cells treated with or without SPARC overexpression in combination with radiation, miR-410 mimics and miR-410 inhibitors. Bright field microcsopy pictures showing that cells treated with miR-410 mimics inhibited angiogenesis (A). Angiogenesis was quantified by measuring length of vessels formed in the CAM assay. SPARC treated cells resulted in significant reduction in vessel length in both SK-N-BE(2) (B) and NB1691 cells (C) (control vs. SPARC, $\left.{ }^{* *} \mathrm{P}<0.001\right)$. miR-410 mimic also showed similar effect as SPARC $\left({ }^{* *} \mathrm{P}<0.001\right)$. The SPARC induced inhibition of angiogenesis was reversed in cells treated with miR-410 inhibitor (SPARC vs. SPARC + miR-410 mimic and SPARC vs. SPARC + miR-410 mimic + radiation ${ }^{* *} \mathrm{P}<0.001$ ). In silico analysis showing that miR-410 targets VEGF-A mRNA at position 344, 359, 390 and 1632 (D). (E) RT-PCR analysis showing that overexpression of SPARC resulted in increased expression of miR-410 levels and addition of miR-410 inhibitors shows decrease in miR-410 expression (SPARC vs. SPARC + miR-410 inhibitor, $\left.{ }^{*} \mathrm{P}=0.028,{ }^{* *} \mathrm{P}=0.003,{ }^{* * *} \mathrm{P}=0.0003\right)$. 


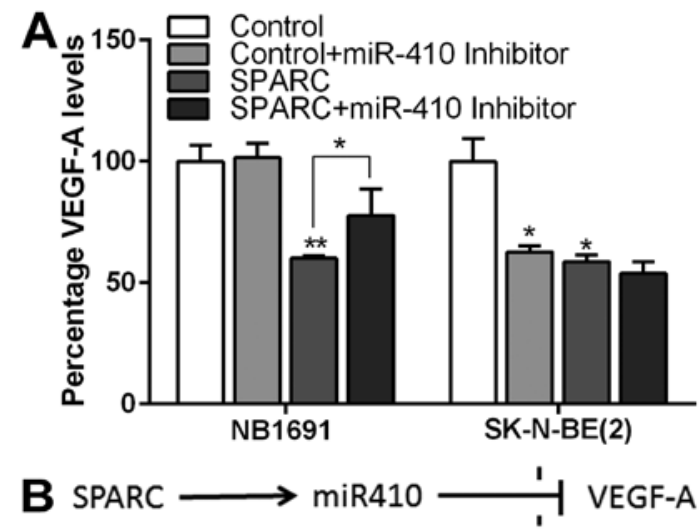

Figure 5. SPARC regulates VEGF-A expression through miR-410. The VEGF-A expression levels in NB1691 and SK-N-BE(2) in cell culture supernatants were measured by ELISA. SPARC overexpression reduced levels of VEGF-A in both cell lines. (A) Addition of miR-410 inhibitor reversed the effect of miR-410 in NB1691 cell line (SPARC vs. SPARC + miR-410 inhibitor ${ }^{*} \mathrm{P}<0.05$, control vs. SPARC $\left.{ }^{*} \mathrm{P}<0.05,{ }^{* *} \mathrm{P}<0.001\right)$. Angiogenesis in neuroblastoma is primarily mediated by VEGF-A. (B) The present study shows that overexpression of SPARC induces expression of miR-410, which specifically inhibits VEGF-A thereby inhibiting angiogenesis.

miR-410 levels in tumor samples collected from mice treated with SPARC overexpressing plasmid. Our results show that SPARC overexpression significantly increased miR-410 levels in NB1691 cells $(\mathrm{P}<0.05)$ and SK-N-BE $(2)$ cells $(\mathrm{P}<0.001)$ and addition of miR-410 inhibitor showed suppression of SPARC induced miR-410 expression in both SK-N-BE(2) and NB1691 cells (Fig. 4E).

SPARC-induced downregulation of VEGF-A is mediated by $m i R-410$. To further validate our findings, we looked for secreted levels of VEGF-A using ELISA in conditioned media used for the CAM (Fig. 5A). We observed that SPARC overexpression alone decreased VEGF-A protein levels by $40 \%$ in NB1691 cells $(\mathrm{P}<0.001)$ and $42 \%$ in SK-N-BE(2) cells $(\mathrm{P}<0.05)$ (Fig. 5A). Addition of miR-410 inhibitor to SPARC overexpressed cells significantly rescued VEGF-A to $77 \%$ of controls $(\mathrm{P}=0.05)$ in NB1691, whereas in $\mathrm{SK}-\mathrm{N}-\mathrm{BE}(2)$ cells no such reversal was observed; $\mathrm{P}$-value represents change in VEGF-A protein levels in culture media compared to controls in 3 replicates.

\section{Discussion}

Angiogenesis is the process by which new blood vessels develop from pre-existing vasculature. This process of angiogenesis provides an efficient way for tumor cells to leave their primary site and enter the blood stream resulting in metastasis. Angiogenesis is a crucial factor for cancer progression in neuroblastoma (33-35). Neuroblastoma (NB) is the most common extracranial solid cancer which originates from developing cells of sympathetic nervous system in children. The invasive and hyper-vascular nature of the high-risk neuroblastoma makes it highly metastatic and refractory to therapy (36). Current therapy for high-risk neuroblastoma is multimodal and includes chemotherapy, surgery, radiation therapy, hematopoietic stem cell transplantation and immunotherapy. It is evident from various studies that radiation intensifies angiogenesis by upregulating angiogenic agents (37), making radiation therapy somewhat counterproductive. Targeting this radiation induced amplification of angiogenesis may be a better therapeutic addition for the treatment of NB. We have previously demonstrated that SPARC expression inversely correlated with angiogenesis (22), indicating that SPARC expression can be used as a modulator of angiogenesis. SPARC is known to be both a proand an anti-oncogenic marker. In neuroblastomas, however, there is an inverse correlation between SPARC expression levels and the stage of tumors (36). There also appears to a link between angiogenesis and SPARC expression levels as seen from our studies. Notably, the expression of SPARC is found to be low in neuroblastoma tumors (19) making SPARC a possible anti-angiogenic molecule for therapeutic intervention. The goal of this study was to demonstrate that SPARC overexpression can be a possible option for the suppression of angiogenesis in neuroblastomas. Our results here have demonstrated that SPARC overexpression suppresses angiogenesis. Therefore, to pursue this goal, we first used an in vivo mouse model to confirm the effect of SPARC overexpression on angiogenesis. We observed that the overexpression of SPARC suppressed formation of new blood vessels confirming its antiangiogenic effect. This result was more pronounced when SPARC transfection was combined with ionizing radiation. SPARC overexpression also suppressed the moderate increase in vasculature seen after radiation. Our results are in agreement with the study by Chleski and colleagues who showed that SPARC protein secreted by schwann cells surrounding neuroblastoma tumors inhibits angiogenesis (18). They also showed that full length SPARC protein and a SPARC peptide were able to inhibit angiogenesis and block growth in preclinical models of neuroblastoma tumors (23). Though the present study showed that radiation increased angiogenesis moderately, the results were not statistically significant. We also observed that radiated tumors showed increased tumor size, but this was not consistent in all radiation treated mice. Previously other researchers have demonstrated that low doses of radiation can promote tumor growth, metastasis and also enhance angiogenesis (38), therefore, suppression of this lowdose radiation induced angiogenesis can be therapeutically very useful. We see that SPARC suppresses angiogenesis, but until now no clear mechanism has been proposed for the possible antiangiogenic effect of SPARC.

Angiogenesis is mediated by several factors such as the vascular endothelial growth factor (VEGF), the fibroblast growth factor (FGF), epidermal growth factor (EGF), the angiopoietins (Ang-1 and Ang-2) and the platelet derived growth factor (PDGF) (34). Of these, VEGF is the most common, best studied and as seen in the present study the most overexpressed angiogenic factor in neuroblastoma cells and tissues. This in vivo study showed that SPARC overexpression with or without radiation suppressed expression of VEGF-A. This result is also supported by in vitro experiments in which western blot data on neuroblastoma cell lines NB1691 and SK-N-BE(2) showed reduced expression of VEGF-A protein levels when SPARC was overexpressed. Our previous study has shown that SPARC overexpression downregulates VEGF-A in neuroblastoma cells by inhibiting Stat 3 phosphorylation partially mediated by notch signaling (22). Though this pathway somewhat defines 
mechanistically the downregulation of VEGF-A, it fails to explain the precise molecular players directly involved in inhibiting VEGF-A mediated angiogenesis. A recent study reported that VEGF-A has a possible anti-necrotic effect (39), indicating that VEGF-A under certain conditions can behave as a protective agent for the promotion of cell growth. It was reported that SPARC overexpression induces endothelial cell apoptosis and inhibited angiogenesis (22). Though the observations are valid, the mechanism detailed is circuitous and derivative of the observations. Similar observations were made in gastric cancer where, overexpression of SPARC was shown to inhibit VEGF-mediated angiogenesis (40), but no clear mechanistic pathway was elucidated in that study. In the present study, we see that miR-410 targets the expression of VEGF-A. We observed that among the 71 miRNAs targeting VEGF-A, miR-410 had a significantly higher number of target sites (4 target sites). A preliminary microarray analysis showed that the miR-410 was differentially expressed in SPARC overexpressed NB1691 cells (data not shown). This was further validated using miR-410 mimics and inhibitors. Similar to the results in our study, miR-410 has been shown to be a tumor suppressor miRNA in controlling angiogenesis in other studies (41), moreover, in pancreatic cancer, overexpression of miR-410 suppressed cell growth, migration and angiogenesis by blocking VEGF and ERK signaling pathways (42). Another study done in mice employed the use of eye drops containing miR-410 to effectively treat retinal neovascularization (RNV) by blocking VEGF mediated angiogenesis (41). A recent study showed miR-410 overexpression resulted in better suppression of VEGF expression than other VEGF targeting miRNAs (43). Furthermore, studies confirm that miR-410 directly binds to VEGF 3'-UTR region (43). This finding strengthens our results and validate that miR-410 is a vital suppressor of angiogenesis and is modulated by SPARC. Notably, miR-410 is also predicted to target TNFSF11/ RANKL among others. TNFSF11/RANKL (tumor necrosis factor ligand superfamily member $11 /$ receptor activator of nuclear factor kappa-B ligand) is known to affect the immune system and controls bone regeneration and remodeling (44). It is known that bone marrow infiltrated neuroblastoma is considered an adverse prognostic factor; with $>50 \%$ of patients showing bone marrow infiltration metastasis at diagnosis (45). Another molecule that is strongly predicted to be a target of miR-410 is NIPBL. NIPBL (Nipped-Blike protein), also known as delangin or SCC2 homolog is a marker for poor prognosis and promotes chemotherapy resistance (46). As we have previously discussed, metastatic neuroblastomas show little to no expression of SPARC and SPARC overexpression is known to induce expression of miR-410 by a yet unknown mechanism. Therefore, the overexpression of SPARC can suppress the expression of both TNFSF11/RANKL and NIPBL via miR-410 and may be a mechanism by which SPARC overexpressed cells show decreased proliferation (16). Though the present study is focused on VEGF-A mediated angiogenesis, the implication of miR-410 expression are beyond the scope of this study.

Notably, we observed that SPARC overexpression reduced secreted VEGF-A levels and this effect was reversed by adding miR-410 inhibitor in NB1691 cells and not in SK-N-BE(2) cells. Though SPARC reduced VEGF-A levels in SK-N-BE(2) cells, blocking miR-410 using an anti-miR-410 failed to rescue VEGF-A levels. This may be due to SK-N-BE(2) being a p53 mutant cell line and NB1691 being p53 wild-type cell line, but the mechanism is still unclear. Interestingly, a study has shown that wild-type p53 alters VEGF expression by binding to its promoter (47). The molecular mechanisms involved in SPARC regulated angiogenesis in tumors with deregulated p53 needs to be further elucidated. Furthermore, another recent study showed that p53 possesses dsRNA exonuclease activity (48), since the use of miR-410 inhibitors involves the formation of dsRNA for its functioning, it is very likely that the cytoplasmic mt-p53 of SK-N-BE(2) actively degrades this miR-410 inhibitory complex with greater efficiency than the wt-p53 of NB1691 cells. This correlates with the observation that miR-410 inhibitor treated SK-N-BE(2) showed reduced rescue of angiogenesis when compared to NB1691 cells. Functions of both micro-RNAs and siRNAs involve similar mechanisms, and mammalian cells are known to show varying degree of resistance to this RNAi mechanism (49), this may also explain why NB1691 and SK-N-BE(2) show variation in VEGF-A rescue. Furthermore, the addition of miR-410 inhibitor to SPARC overexpressed cells did show reversal of miR-410 in both NB1691 and SK-N-BE(2) cells, this inhibitory effect was more pronounced in SK-N-BE(2) cells than in NB1691 cells. This observation may be due to the fact that even though SPARC overexpression increases the expression of miR-410, the addition of miR-410 inhibitor may render miR-410 functionally unavailable due to compliment sequence binding.

MicroRNAs still hold a lot of potential for therapeutic applicability. We see that the control of angiogenesis by miRNAs is well documented; miRNAs have been shown to control both pro- and anti-angiogenic pathways. In ovarian cancer, miR-497 has been shown to block VEGF signaling and this results in suppression of angiogenesis by inhibition of PI3K/AKT and ERK signaling pathways (50). Moreover, miR-503 was shown to inhibit angiogenesis by simultaneously inhibiting VEGF-A and FGF in hepatocellular carcinoma (HCC) (51). In colorectal cancer, miR-126 was shown to be epigenetically silenced leading to tumor invasion and angiogenesis (52). Upregulation of miR-126 resulted in reduced VEGF expression, leading to suppression of angiogenesis. Upregulation of miR-107 in glioma cells have also been shown to inhibit VEGF expression (53). To the best of our knowledge, this study is the first to show the possible mechanistic role of SPARC in controlling angiogenesis via miR-410 in high-risk neuroblastomas.

The present study shows that VEGF-mediated angiogenesis can be attenuated either by increasing SPARC expression or by directly upregulating miR-410. In the subset of patients with high-risk neuroblastoma who are treated with radiation that show increased vascularization, SPARC and/or miR-410 can be considered as a valuable add-on therapeutic option.

\section{Acknowledgements}

This present study was supported by the NCI grant R01CA147792 to C.S.G. The authors wish to thank Angela Daniels for help with animal experimentation. 


\section{References}

1. Maris JM, Hogarty MD, Bagatell R and Cohn SL: Neuroblastoma. Lancet 369: 2106-2120, 2007.

2. Pinto NR, Applebaum MA, Volchenboum SL, Matthay KK, London WB, Ambros PF, Nakagawara A, Berthold F, Schleiermacher G, Park JR, et al: Advances in risk classification and treatment strategies for neuroblastoma. J Clin Oncol 33: 3008-3017, 2015

3. Yu DM, Huynh T, Truong AM, Haber M and Norris MD: ABC transporters and neuroblastoma. Adv Cancer Res 125: 139-170, 2015.

4. Scaldaferri F, Vetrano S, Sans M, Arena V, Straface G, Stigliano E, Repici A, Sturm A, Malesci A, Panes J, et al: VEGF-A links angiogenesis and inflammation in inflammatory bowel disease pathogenesis. Gastroenterology 136: 585-95.e5, 2009.

5. Kowshik J, Giri H, Kishore TK, Kesavan R, Vankudavath RN, Reddy GB, Dixit M and Nagini S: Ellagic acid inhibits VEGF/ VEGFR2, PI3K/Akt and MAPK signaling cascades in the hamster cheek pouch carcinogenesis model. Anticancer Agents Med Chem 14: 1249-1260, 2014

6. Maris JM: Recent advances in neuroblastoma. N Engl J Med 362: 2202-2211, 2010

7. Kushner BH, LaQuaglia MP, Bonilla MA, Lindsley K, Rosenfield N, Yeh S, Eddy J, Gerald WL, Heller G and Cheung NK: Highly effective induction therapy for stage 4 neuroblastoma in children over 1 year of age. J Clin Oncol 12: 2607-2613, 1994.

8. De Ioris MA, Crocoli A, Contoli B, Garganese MC, Natali G, Tomà $\mathrm{P}$, Jenkner A, Boldrini R, De Pasquale MD, Milano GM, et al: Local control in metastatic neuroblastoma in children over 1 year of age. BMC Cancer 15: 79, 2015.

9. Yu AL, Gilman AL, Ozkaynak MF, London WB, Kreissman SG, Chen HX, Smith M, Anderson B, Villablanca JG, Matthay KK, et al; Children's Oncology Group: Anti-GD2 antibody with GM-CSF, interleukin-2, and isotretinoin for neuroblastoma. $\mathrm{N}$ Engl J Med 363: 1324-1334, 2010.

10. Jones C, Mackay A, Grigoriadis A, Cossu A, Reis-Filho JS, Fulford L, Dexter T, Davies S, Bulmer K, Ford E, et al: Expression profiling of purified normal human luminal and myoepithelial breast cells: Identification of novel prognostic markers for breast cancer. Cancer Res 64: 3037-3045, 2004

11. Lien HC, Hsiao YH, Lin YS, Yao YT, Juan HF, Kuo WH, Hung MC, Chang KJ and Hsieh FJ: Molecular signatures of metaplastic carcinoma of the breast by large-scale transcriptional profiling: Identification of genes potentially related to epithelialmesenchymal transition. Oncogene 26: 7859-7871, 2007.

12. Chen J, Wang M, Xi B, Xue J, He D, Zhang J and Zhao Y: SPARC is a key regulator of proliferation, apoptosis and invasion in human ovarian cancer. PLoS One 7: e 42413, 2012.

13. Sato T, Oshima T, Yamamoto N, Yamada T, Hasegawa $\mathrm{S}$, Yukawa N, Numata K, Kunisaki C, Tanaka K, Shiozawa M, et al: Clinical significance of SPARC gene expression in patients with gastric cancer. J Surg Oncol 108: 364-368, 2013.

14. Shin M, Mizokami A, Kim J, Ofude M, Konaka H, Kadono Y, Kitagawa Y, Miwa S, Kumaki M, Keller ET, et al: Exogenous SPARC suppresses proliferation and migration of prostate cancer by interacting with integrin $\beta 1$. Prostate 73: 1159-1170, 2013.

15. DiMartino JF, Lacayo NJ, Varadi M, Li L, Saraiya C, Ravindranath Y, Yu R, Sikic BI, Raimondi SC and Dahl GV: Low or absent SPARC expression in acute myeloid leukemia with MLL rearrangements is associated with sensitivity to growth inhibition by exogenous SPARC protein. Leukemia 20: 426-432, 2006.

16. Bhoopathi P, Gorantla B, Sailaja GS, Gondi CS, Gujrati M, Klopfenstein JD and Rao JS: SPARC overexpression inhibits cell proliferation in neuroblastoma and is partly mediated by tumor suppressor protein PTEN and AKT. PLoS One 7: e36093, 2012.

17. Chlenski A, Liu S, Guerrero LJ, Yang Q, Tian Y, Salwen HR, Zage P and Cohn SL: SPARC expression is associated with impaired tumor growth, inhibited angiogenesis and changes in the extracellular matrix. Int J Cancer 118: 310-316, 2006.

18. Chlenski A, Liu S, Crawford SE, Volpert OV, DeVries GH, Evangelista A, Yang Q, Salwen HR, Farrer R, Bray J, et al: SPARC is a key Schwannian-derived inhibitor controlling neuroblastoma tumor angiogenesis. Cancer Res 62: 7357-7363, 2002.

19. Feng $J$ and Tang L: SPARC in tumor pathophysiology and as a potential therapeutic target. Curr Pharm Des 20: 6182-6190, 2014.
20. Gorantla B, Asuthkar S, Rao JS, Patel J and Gondi CS Suppression of the uPAR-uPA system retards angiogenesis, invasion, and in vivo tumor development in pancreatic cancer cells. Mol Cancer Res 9: 377-389, 2011.

21. Gondi CS, Lakka SS, Yanamandra N, Siddique K, Dinh DH, Olivero WC, Gujrati M and Rao JS: Expression of antisense uPAR and antisense uPA from a bicistronic adenoviral construct inhibits glioma cell invasion, tumor growth, and angiogenesis. Oncogene 22: 5967-5975, 2003

22. Gorantla B, Bhoopathi P, Chetty C, Gogineni VR, Sailaja GS, Gondi CS and Rao JS: Notch signaling regulates tumorinduced angiogenesis in SPARC-overexpressed neuroblastoma. Angiogenesis 16: 85-100, 2013.

23. Chlenski A, Guerrero LJ, Peddinti R, Spitz JA, Leonhardt PT, Yang Q, Tian Y, Salwen HR and Cohn SL: Anti-angiogenic SPARC peptides inhibit progression of neuroblastoma tumors. Mol Cancer 9: 138, 2010.

24. Liao D and Johnson RS: Hypoxia: A key regulator of angiogenesis in cancer. Cancer Metastasis Rev 26: 281-290, 2007.

25. Mabjeesh NJ and Amir S: Hypoxia-inducible factor (HIF) in human tumorigenesis. Histol Histopathol 22: 559-572, 2007.

26. Liu Y, Kudo K, Abe Y, Aoki M, Hu DL, Kijima H and Nakane A: Hypoxia expression in radiation-induced late rectal injury. $\mathbf{J}$ Radiat Res (Tokyo) 49: 261-268, 2008.

27. Simons M: Integrative signaling in angiogenesis. Mol Cell Biochem 264: 99-102, 2004.

28. Zhang W, Ran S, Sambade M, Huang X and Thorpe PE: A monoclonal antibody that blocks VEGF binding to VEGFR2 (KDR/ Flk-1) inhibits vascular expression of Flk-1 and tumor growth in an orthotopic human breast cancer model. Angiogenesis 5: 35-44, 2002.

29. Hong DS, Garrido-Laguna I, Ekmekcioglu S, Falchook GS, Naing A, Wheler JJ, Fu S, Moulder SL, Piha-Paul S, Tsimberidou AM, et al: Dual inhibition of the vascular endothelial growth factor pathway: A phase 1 trial evaluating bevacizumab and AZD2171 (cediranib) in patients with advanced solid tumors. Cancer 120: 2164-2173, 2014.

30. Waldner MJ and Neurath MF: Targeting the VEGF signaling pathway in cancer therapy. Expert Opin Ther Targets 16: 5-13, 2012.

31. Staton CA, Reed MW and Brown NJ: A critical analysis of current in vitro and in vivo angiogenesis assays. Int $\mathrm{J}$ Exp Pathol 90: 195-221, 2009.

32. John B, Enright AJ, Aravin A, Tuschl T, Sander C and Marks DS: Human MicroRNA targets. PLoS Biol 2: e363, 2004.

33. Ribatti D: Anti-angiogenesis in neuroblastoma. Crit Rev Oncol Hematol 86: 212-221, 2013

34. Roy CS, Karmakar S, Banik NL and Ray SK: Targeting angiogenesis for controlling neuroblastoma. J Oncol 2012: Article ID 782020 2012. doi:10.1155/2012/782020.

35. Chlenski A, Liu S and Cohn SL: The regulation of angiogenesis in neuroblastoma. Cancer Lett 197: 47-52, 2003.

36. Ribatti D, Marimpietri D, Pastorino F, Brignole C, Nico B, Vacca A and Ponzoni M: Angiogenesis in neuroblastoma. Ann NY Acad Sci 1028: 133-142, 2004

37. Gorski DH1, Beckett MA, Jaskowiak NT, Calvin DP, Mauceri HJ, Salloum RM, Seetharam S, Koons A, Hari DM, Kufe DW, et al: Blockage of the vascular endothelial growth factor stress response increases the antitumor effects of ionizing radiation. Cancer Res 59: 3374-3378, 1999.

38. Sofia Vala I1, Martins LR, Imaizumi N, Nunes RJ, Rino J, Kuonen F, Carvalho LM, Rüegg C, Grillo IM, Barata JT, et al: Low doses of ionizing radiation promote tumor growth and metastasis by enhancing angiogenesis. PLoS One 5: e11222, 2010.

39. El Ghazi F, Desfeux A, Brasse-Lagnel C, Roux C, Lesueur C, Mazur D, Remy-Jouet I, Richard V, Jégou S, Laudenbach V, et al: NO-dependent protective effect of VEGF against excitotoxicity on layer VI of the developing cerebral cortex. Neurobiol Dis 45: 871-886, 2012.

40. Zhang JL, Chen GW, Liu YC, Wang PY, Wang X, Wan YL, Zhu J, Gao HQ, Yin J, Wang W, et al: Secreted protein acidic and rich in cysteine (SPARC) suppresses angiogenesis by down-regulating the expression of VEGF and MMP-7 in gastric cancer. PLoS One 7: e44618, 2012.

41. Chen N, Wang J, Hu Y, Cui B, Li W, Xu G, Liu L and Liu S: MicroRNA-410 reduces the expression of vascular endothelial growth factor and inhibits oxygen-induced retinal neovascularization. PLoS One 9: e95665, 2014. 
42. Guo R, Gu J, Zhang Z, Wang Y and Gu C: MicroRNA-410 functions as a tumor suppressor by targeting angiotensin II type 1 receptor in pancreatic cancer. IUBMB Life 67: 42-53, 2015.

43. Zhao D, Jia P, Wang W and Zhang G: VEGF-mediated suppression of cell proliferation and invasion by miR-410 in osteosarcoma. Mol Cell Biochem 400: 87-95, 2015.

44. Hanada R, Hanada T, Sigl V, Schramek D and Penninger JM: RANKL/RANK-beyond bones. J Mol Med (Berl) 89: 647-656, 2011.

45. Morandi F, Corrias MV and Pistoia V: Evaluation of bone marrow as a metastatic site of human neuroblastoma. Ann NY Acad Sci 1335: 23-31, 2015.

46. Xu W, Ying Y, Shan L, Feng J, Zhang S, Gao Y, Xu X, Yao Y, Zhu $\mathrm{C}$ and Mao W: Enhanced expression of cohesin loading factor NIPBL confers poor prognosis and chemotherapy resistance in non-small cell lung cancer. J Transl Med 13: 153, 2015.

47. Farhang Ghahremani M, Goossens S, Nittner D, Bisteau X, Bartunkova S, Zwolinska A, Hulpiau P, Haigh K, Haenebalcke L, Drogat $\mathrm{B}$, et al: $\mathrm{p} 53$ promotes VEGF expression and angiogenesis in the absence of an intact p21-Rb pathway. Cell Death Differ 20 888-897, 2013.
48. Grinberg S, Teiblum G, Rahav G and Bakhanashvili M: p53 in cytoplasm exerts $3^{\prime} \rightarrow 5^{\prime}$ exonuclease activity with dsRNA. Cell Cycle 9: 2442-2455, 2010.

49. Zheng ZM, Tang S and Tao M: Development of resistance to RNAi in mammalian cells. Ann NY Acad Sci 1058: 105-118, 2005.

50. Wang W, Ren F, Wu Q, Jiang D, Li H and Shi H: MicroRNA-497 suppresses angiogenesis by targeting vascular endothelial growth factor A through the PI3K/AKT and MAPK/ERK pathways in ovarian cancer. Oncol Rep 32: 2127-2133, 2014.

51. Zhou B, Ma R, Si W, Li S, Xu Y, Tu X and Wang Q: MicroRNA503 targets FGF2 and VEGFA and inhibits tumor angiogenesis and growth. Cancer Lett 333: 159-169, 2013.

52. Zhang Y, Wang X, Xu B, Wang B, Wang Z, Liang Y, Zhou J, $\mathrm{Hu} \mathrm{J}$ and Jiang B: Epigenetic silencing of miR-126 contributes to tumor invasion and angiogenesis in colorectal cancer. Oncol Rep 30: 1976-1984, 2013.

53. Chen L, Li ZY, Xu SY, Zhang XJ, Zhang Y, Luo K and Li WP: Upregulation of miR-107 inhibits glioma angiogenesis and VEGF expression. Cell Mol Neurobiol 36: 113-120, 2015. 